\title{
Kinh nghiệm quản lý chuỗi cung ứng của doanh nghiệp điện tử tại Việt Nam: Vai trò của các thành phần chia sẻ thông tin
}

\section{Experiences on electronic supply chain management of electronic companies in Vietnam: The roles of information sharing components}

\author{
Nguyễn Thị Đức Nguyên ${ }^{1 *}$, Nguyễn Thị Hoàng Mai ${ }^{1}$ \\ ${ }^{1}$ Trường Đại học Bách khoa - Đại học Quốc Gia Thành phố Hồ Chí Minh, Việt Nam \\ *Tác giả liên hệ, Email: ntdnguyen@hcmut.edu.vn
}

THÔNG TIN

DOI: $10.46223 / \mathrm{HCMCOUJS.}$ econ.vi.16.1.566.2021

Ngày nhận: 28/06/2020

Ngày nhận lại: 09/08/2020

Duyệt đăng: 16/08/2020

Tì khóa:

chia sẻ thông tin, hiệu quả chuỗi cung ứng, doanh nghiệp điện tử, Việt Nam

\section{TÓM TẮT}

Trong bối cảnh nhiều doanh nghiệp trong chuỗi cung ứng điện tử đang đối mặt với những cơ hội cũng như thách thức khi tham gia chuỗi cung ứng toàn cầu, vấn đề đặt ra liệu việc tận dụng dòng thông tin chia sẻ trong chuỗi cung ứng cũng như quản trị dòng thông tin này hiệu quả có thể góp phần cải thiện hiệu quả quản lý chuỗi cung ứng. Nghiên cứu này tập trung đúc kết kinh nghiệm thực tiễn quản lý chuỗi cung ứng của hai doanh nghiệp điện tử điển hình tại Việt Nam nhằm xác định các thành phần chính của chia sẻ thông tin trong chuỗi cung ứng điện tử. Kết quả nghiên cứu tìm ra được bốn thành phần chính của chia sẻ thông tin có tác động lên hiệu quả chuỗi cung ứng điện tử của các doanh nghiệp điện tử tại Việt Nam, bao gồm chia sẻ thông tin với nhà cung cấp, chia sẻ thông tin với khách hàng, chia sẻ thông tin liên chức năng trong doanh nghiệp và chia sẻ kiến thức trong nội bộ doanh nghiệp. Theo đó, sự hợp tác tốt giữa các đối tác trong chuỗi cung ứng giúp chia sẻ thông tin thường xuyên và có chất lượng thông tin cao, đồng thời nhà quản lý doanh nghiệp đóng vai trò rất quan trọng trong việc thúc đẩy chia sẻ thông tin hiệu quả trong chuỗi cung ứng. Nhìn chung, nghiên cứu này là tài liệu tham khảo hữu ích cho các doanh nghiệp trong việc xây dựng kế hoạch chiến lược phù hợp để cải thiện dòng thông tin trong chuỗi cung ứng và nâng cao hiệu quả hoạt động chuỗi cung ứng của doanh nghiệp sản xuất nói chung, đặc biệt chuỗi cung ứng điện tử tại Việt Nam.

\section{ABSTRACT}

In the context of many businesses in the electronic supply chain are facing opportunities and challenges when participating in the global supply chain, the question is whether to take advantage of the information sharing flow in the supply chain as well as effective information management can contribute to improve supply chain management performance. This study focuses on the practical experiences of supply chain management of two typical electronic enterprises in Vietnam in order to identify the key components of
Keywords:

information sharing, supply chain performance, electronic company, Vietnam 
information sharing in electronic supply chains. The findings identify four key components of information sharing that affect the efficiency of electronic supply chain of the electronic companies in Vietnam, including information sharing with suppliers, information sharing with customers, cross-functional information sharing and intra-organizational knowledge sharing. Accordingly, close cooperation among supply chain partners helps to share information regularly and has a high information quality, and business managers play a very important role in promoting effective information sharing in the supply chain. Overall, this study serves as a helpful reference for managers to have appropriately strategic plans for improving information flow in the supply chain and the supply chain efficiency of manufacturing companies in general, especially electronic supply chain in Vietnam.

\section{Giới thiệu}

Trong những năm gần đây, ngành điện tử Việt Nam đang có bước phát triển đáng kể và là một trong sáu ngành kinh tế trọng điểm của Việt Nam. Theo số liệu từ Tổng cục thống kê (2019), tổng kim ngạch xuất khẩu các sản phẩm điện tử, máy tính, điện thoại và linh kiện năm 2018 đạt hơn 78 tỷ USD, chiếm $32 \%$ kim ngạch xuất khẩu cả nước, gấp khoảng 2.5 lần ngành dệt may và gấp khoảng 5 lần ngành da giày, dẫn đầu cả nước về kim ngạch xuất khẩu đối với các ngành công nghiệp chế biến và chế tạo. Ngành công nghiệp điện tử được đánh giá là ngành công nghiệp mũi nhọn, trọng điểm của cả nước, đã có những phát triển vượt bậc, tiên phong trong việc tổ chức và cơ cấu mạng sản xuất toàn cầu (Le \& Nguyen, 2009). Cho nên, ngành này luôn được ưu tiên đầu tư phát triển (Tran \& Huynh, 2016) và thu hút được nguồn nhân lực chất lượng cao cả về kỹ thuật công nghệ đến trình độ quản lý (Q. M. Nguyen \& Nguyen, 2013). Tuy nhiên, trong bối cảnh chuỗi cung ứng hiện nay, các doanh nghiệp điện tử tại Việt Nam đang đứng trước nhiều cơ hội và thách thức của hội nhập toàn cầu. Tham gia vào chuồi giá trị hay chuỗi cung ứng được xem là một trong những giải pháp có tính chiến lược đối với các doanh nghiệp Việt Nam (T. H. Nguyen, 2014); đồng thời, cũng tạo ra nhiều thách thức cho doanh nghiệp Việt về chất lượng sản phẩm, chi phí tồn kho, thời gian giao hàng... Để đáp ứng với những thách thức này, các doanh nghiệp không chỉ tập trung vào hoạt động quản trị và vận hành độc lập, mà cần phải có sự phối hợp hoạt động với các nhà cung cấp và khách hàng trong chuỗi cung ứng. Bên cạnh đó, để nâng cao giá trị gia tăng và chất lượng tăng trưởng cho ngành điện tử, việc tăng cường liên kết các doanh nghiệp trong chuỗi cung ứng là cần thiết (VEIA, 2017). Hiện nay, các doanh nghiệp tham gia vào chuỗi cung ứng điện tử, đặc biệt là các doanh nghiệp tham gia vào chuỗi cung ứng toàn cầu đều xem việc chia sẻ thông tin và tri thức là yêu cầu và động lực của sự phát triển. Điều này thúc đẩy các doanh nghiệp trong chuỗi cung ứng điện tử nên tận dụng dòng thông tin trong chuỗi cung ứng cũng như quản trị thông tin hiệu quả để cải thiện hiệu quả hoạt động chuỗi cung ứng.

Các nghiên cứu trên thế giới đã đưa ra được một số thành phần chia sẻ thông tin trong các chuỗi cung ứng khác nhau, như là chia sẻ thông tin với nhà cung cấp (e.g., Asamoah, AndohBaidoo, \& Agyei-Owusu, 2016; Baihaqi \& Sohal, 2013; Barratt \& Barratt, 2011; Devaraj, Krajewski, \& Wei, 2007; Flynn, Huo, \& Zhao, 2010; Huo, Zhao, \& Zhou, 2014; Kocoglu, İmamoğlu, İnce, \& Keskin, 2011; Sezen, 2008), chia sẻ thông tin với khách hàng (e.g., Asamoah et al., 2016; Baihaqi \& Sohal, 2013; Barratt \& Barratt, 2011; Boon-itt \& Wong, 2011; Devaraj et al., 2007; Huo et al., 2014; Klein \& Rai, 2009; Kocoglu et al., 2011; Zhou \& Benton, 2007), chia sẻ thông tin liên chức năng (e.g., Asamoah et al., 2016; Baihaqi \& Sohal, 2013; Boon-itt \& Wong, 
2011; Eng, 2006; Flynn et al., 2010; Huo et al., 2014; Kocoglu et al., 2011; Martin \& Grbac, 2003), chia sẻ kiến thức trong nội bộ doanh nghiệp (e.g., Akgün, Keskin, Byrne, \& Aren, 2007; Bontis \& Serenko, 2009; Calantone, Cavusgil, \& Zhao, 2002; Chatzoudes \& Chatzoglou, 2015; Eng, 2006; Kocoglu et al., 2011)... Các nghiên cứu này được thực hiện tại bối cảnh khác nhau, tại nhiều doanh nghiệp thuộc nhiều ngành nghề khác nhau. Ngoài ra, có ít nghiên cứu xem xét tác động của các thành phần chia sẻ thông tin đến hiệu quả chuỗi cung ứng, mà chỉ xem xét đến hiệu quả doanh nghiệp trên các khía cạnh riêng lẻ về mặt hiệu quả phân phối hoặc chi phí vận hành.

Bên cạnh đó, cho đến hiện tại chỉ có một số ít nghiên cứu về chia sẻ thông tin trong chuỗi cung ứng được nghiên cứu trong bối cảnh Việt Nam, ví dụ như nghiên cứu ảnh hưởng của niềm tin và trao đổi thông tin điện tử đến kết quả chuỗi cung ứng ngành bán lẻ (T. H. Nguyen, 2014), xem xét chất lượng thông tin trong quản lý chất lượng chuỗi cung ứng (T. T. H. Nguyen et al., 2015)... Những nghiên cứu này chưa xác định được các thành phần cũng như phân tích cụ thể cho từng thành phần chia sẻ thông tin trong chuỗi cung ứng. Việc xác định các thành phần chia sẻ thông tin tác động lên hiệu quả chuỗi cung ứng giúp cho các doanh nghiệp điện tử có được cái nhìn đúng đắn và có kế hoạch phù hợp cho hoạt động quản lý và chia sẻ thông tin, từ đó nâng cao năng lực cạnh tranh. Do đó, nghiên cứu này tập trung nhận diện các thành phần chính của chia sẻ thông tin trong chuỗi cung ứng có ảnh hưởng đến hiệu quả chuỗi cung ứng thông qua nghiên cứu kinh nghiệm quản lý chuỗi cung ứng của doanh nghiệp điện tử điển hình nhằm đúc kết các bài học hữu ích cho các doanh nghiệp trong ngành điện tử và các ngành khác.

\section{Phương pháp nghiên cứu}

Nghiên cứu này được thực hiện thông qua hai phương pháp chính là tổng quan lý thuyết theo cách tiếp cận của Creswell và Creswell (2018) và nghiên cứu tình huống doanh nghiệp theo cách tiếp cận của Yin (2015).

Tổng quan lý thuyết giúp tổng hợp, phân tích kết quả của các nghiên cứu khác có liên quan chặt chẽ với nghiên cứu được thực hiện, tìm ra những khoảng trống trong nghiên cứu cũng như các cơ hội nghiên cứu (Creswell \& Creswell, 2018).

Nghiên cứu tình huống là một phương pháp xem xét, điều tra thực nghiệm các hiện tượng đang hiện hữu theo chiều sâu và chi tiết các vấn đề tại một đơn vị, trong một tình huống thực, cụ thể (Dempsey \& Dempsey, as cited in Luck, Jackson, \& Usher, 2006; Yin, 2015). Trọng tâm của nghiên cứu tình huống là trả lời câu hỏi về cách thức và lý do; cho nên, tình huống nghiên cứu cần liên quan đến hiện tượng nghiên cứu trong một bối cảnh thời gian xác định, không bị tác động bởi người nghiên cứu (Baxter \& Jack, 2008). Nghiên cứu tình huống áp dụng nhiều cơ sở lý thuyết phù hợp và kết hợp nhiều phương pháp với nhau như phân tích nội dung định tính, quan sát thông thường, phỏng vấn sâu, khảo sát thu thập dữ liệu (Coombs \& Holladay, 2011). Cách thức thực hiện và kết quả của các nghiên cứu tình huống sẽ khác nhau tùy thuộc vào bối cảnh mà nghiên cứu đang triển khai, các giả định triết lý được đặt ra (Ragin, 1992, as cited in Luck et al., 2006). Đặc biệt, quá trình thu thập dữ liệu tại hiện trường luôn gồm việc thu thập dữ liệu và xử lý dữ liệu cùng với những ghi chú cần thiết (Eisenhardt \& Graebner, 2007). Việc thu thập dữ liệu từ một tình huống thực tế và so sánh với kết quả tổng quan lý thuyết được thực hiện liên tục với nhau nhằm chỉ ra các điểm tương đồng và các điểm khác biệt giữa tình huống nghiên cứu và cơ sở lý thuyết, đồng thời lý giải cho sự khác biệt này (T. D. Nguyen, 2013). Vì vậy, nghiên cứu tình huống là một cách thức được sử dụng phổ biến, phù hợp trong lĩnh vực khoa học xã hội và chăm sóc sức khỏe (Luck et al., 2006).

Tình huống được lựa chọn nghiên cứu trong nghiên cứu này là hai doanh nghiệp điển hình trong chuỗi cung ứng điện tử tại Việt Nam, khác nhau về quy mô doanh nghiệp và đặc thù chuyên môn sản xuất. 
Công ty $\mathrm{A}$ là doanh nghiệp gia công lắp ráp linh kiện, sản xuất khuôn mẫu chính xác và động cơ rung cho các thiết bị điện tử như điện thoại, đồng hồ đeo tay. Đây là doanh nghiệp 100\% vốn đầu tư Nhật Bản, là thành viên của một tập đoàn với 8 nhà máy trên toàn cầu. Công ty $\mathrm{A}$ có $70 \%$ sản lượng đặt hàng là từ công ty mẹ tại Nhật Bản, $30 \%$ gia công lắp ráp linh kiện điện tử cho các khách hàng tại Việt Nam. Sau khoảng thời gian hoạt động 5 năm, số lượng nhân viên trong công ty đạt khoảng 800 người, trong đó $85 \%$ là lao động trực tiếp. Công ty đặc biệt quan tâm đến dòng thông tin trao đổi trong nội bộ tập đoàn, sử dụng hệ thống quản lý thông tin để phục vụ hoạt động sản xuất và chia sẻ thông tin với các thành viên nội bộ trong tập đoàn.

Công ty $\mathrm{B}$ là doanh nghiệp lắp ráp các thiết bị điện tử gia dụng như tivi, tủ lạnh, máy giặt, máy hút bụi. Doanh nghiệp $\mathrm{B}$ là một thành viên của tập đoàn Hàn Quốc, hiện có năng suất trung bình 1.1 triệu sản phẩm/tháng. Số lượng nhân viên lên đến hơn 7000 người, được phân chia thành 12 bộ phận quản lý chính. Số lượng nhà cung cấp hiện tại là 115 , bao gồm nhà cung cấp Việt Nam và nhập khẩu hàng từ các nhà cung cấp nước ngoài. Các nhà cung cấp nước ngoài chiếm tỷ trọng lớn, chủ yếu là các nhà cung cấp từ Hàn Quốc và Trung Quốc, cung cấp các bộ phận chi tiết quan trọng, mang tính chính xác cao như là bo mạch, dây cáp FFC, dây dẫn...Các nhà cung cấp trong nước cung cấp nhiều loại nguyên phụ liệu như linh kiện nhỏ, khuôn mẫu, in ấn, các sản phẩm kèm theo (e.g., ống nối, đầu bàn chải hút sàn, ống lò xo...). Công ty $\mathrm{B}$ nhận đơn đặt hàng trực tiếp từ trụ sở chính và thành phẩm được vận chuyển trực tiếp đến trung tâm phân phối tổng tại từng quốc gia theo điều phối của trụ sở chính. Với số lượng đối tác và nhân viên lớn, để việc quản lý thông tin hiệu quả trong nội bộ và với các đối tác hiệu quả, công ty liên tục cải tiến hệ thống quản lý tài liệu điện tử và hệ thống thông tin liên lạc thông qua internet, intranet và email.

\section{Kết quả nghiên cứu}

Dựa trên kết quả thu thập, phân tích, so sánh, tổng hợp được từ nghiên cứu tình huống tại công ty $A$ và công ty $B$, có so sánh, đối chiếu với các nghiên cứu trước có liên quan, nghiên cứu đã tìm ra bốn thành phần chính của chia sẻ thông tin trong chuỗi cung ứng có ảnh hưởng đến hiệu quả chuỗi cung ứng điện tử, bao gồm: nhóm các yếu tố thuộc thành phần chia sẻ thông tin với nhà cung cấp (Bảng 1$)$, nhóm các yếu tố thuộc thành phần chia sẻ thông tin với khách hàng (Bảng 2), nhóm các yếu tố thuộc thành phần chia sẻ thông tin liên chức năng trong doanh nghiệp (Bảng 3) và nhóm các yếu tố thuộc thành phần chia sẻ kiến thức trong nội bộ doanh nghiệp (Bảng 4).

Các ký hiệu trong các Bảng 1, Bảng 2, Bảng 3 và Bảng 4 có ý nghĩa như sau:

$\checkmark$ : Các yếu tố được tìm thấy trong nghiên cứu này và tương đồng so với các nghiên cứu trước có liên quan.

X: Các yếu tố được tìm thấy trong nghiên cứu này, nhưng không được tìm thấy ở các nghiên cứu trước có liên quan. 


\section{Bảng 1}

Nhóm các yếu tố thuộc thành phần chia sẻ thông tin với nhà cung cấp

\begin{tabular}{|c|c|c|}
\hline Nghiên cứu trước & Công ty A & Công ty $B$ \\
\hline \multirow{2}{*}{$\begin{array}{l}\checkmark \text { Công ty cung cấp thông } \\
\text { tin dự báo nhu cầu cho các } \\
\text { nhà cung cấp chính } \\
\text { (Asamoah et al., 2016; } \\
\text { Boon-itt \& Wong, 2011; } \\
\text { Klein \& Rai, 2009; Sezen, } \\
\text { 2008) }\end{array}$} & \multicolumn{2}{|c|}{$\begin{array}{l}\checkmark \text { Thông tin dự báo nhu cầu được trao đổi dưới dạng thông tin điện tử với nhiều nhà } \\
\text { cung cấp cả trong và ngoài nước. }\end{array}$} \\
\hline & $\begin{array}{l}\checkmark \text { Thông tin dự báo được chia } \\
\text { sẻ mỗi nửa năm tới các nhà } \\
\text { cung cấp trong nước, và dứ } \\
\text { báo nhu cầu hàng tháng đối } \\
\text { với nhà cung cấp nước ngoài. }\end{array}$ & $\begin{array}{l}\checkmark \text { Nhà cung cấp nước ngoài nhận được thông tin nhu } \\
\text { cầu hàng tháng và nhận fax xác nhận hàng tuần. } \\
\checkmark \text { Nhà cung cấp nội địa nhận được thông tin nhu cầu } \\
\text { hàng tuần và nhận fax xác nhận hàng ngày. }\end{array}$ \\
\hline $\begin{array}{l}\checkmark \text { Công ty chia sẻ kế hoạch } \\
\text { sản xuất với các nhà cung } \\
\text { cấp chính (Asamoah et al., } \\
2016 \text {; Devaraj et al., 2007; } \\
\text { Flynn et al., 2010; Sezen } \\
2008 \text { ) }\end{array}$ & $\begin{array}{l}\text { xĐặc thù là công ty lắp ráp } \\
\text { linh kiện, phụ thuộc nhiều } \\
\text { vào nhà cung cấp chính - } \\
\text { công ty mẹ, vì vâyy kế hoạch } \\
\text { sản xuất chỉ được chia sẻ cho } \\
\text { công ty mẹ, không chia sẻ vói } \\
\text { nhà cung cấp nào khác. }\end{array}$ & $\begin{array}{l}\checkmark \text { Đạc thù là công ty lắp ráp thành phẩm cuối cùng, } \\
\text { thông tin được chia sẻ tới nhà cung cấp chính hàng } \\
\text { ngày, bao gồm thông tin chi tiết khoảng thời gian cụ thể } \\
\text { sản xuất từng mã hàng, mã nguyên vật liệu nhà cung } \\
\text { cấp cần cung ứng, thời gian nguyên vật liệu cần được } \\
\text { vận chuyển... Trên cơ sở đó, nhà cung cấp tính toán sản } \\
\text { lượng, sắp xếp kế hoạch giao hàng hợp lý. }\end{array}$ \\
\hline \multirow{2}{*}{$\begin{array}{l}\checkmark \text { Công ty và các nhà cung } \\
\text { cấp chính chia sẻ thông tin } \\
\text { hoạch định năng lực sản } \\
\text { xuất (Asamoah et al., 2016; } \\
\text { Barratt \& Barratt, } 2011 ; \\
\text { Devaraj et al., 2007; } \\
\text { Kocoglu et al., 2011; } \\
\text { Sezen, 2008) }\end{array}$} & \multicolumn{2}{|c|}{$\begin{array}{l}\checkmark \text { Công ty quan tâm đến việc trao đổi thông tin về năng lực sản xuất với hầu hết các } \\
\text { nhà cung cấp. Thông tin này được kỳ vọng giúp hoạt động quản lý nguồn cung của } \\
\text { công ty hiệu quả hơn, cải thiện các hoạt động hỗ trợ lẫn nhau, giúp doanh nghiệp đánh } \\
\text { giá khả năng phát triển của nhà cung cấp. }\end{array}$} \\
\hline & $\begin{array}{l}\checkmark \text { Công ty thường chia sẻ } \\
\text { thông tin thông qua các cuộc } \\
\text { nói chuyện giữa các nhà lãnh } \\
\text { đạo. }\end{array}$ & $\begin{array}{l}\checkmark \text { Công ty có những chương trình đào tạo cho một số } \\
\text { doanh nghiệp nội địa nằm trong chuỗi cung ứng để giúp } \\
\text { các doanh nghiệp này nâng cao năng suất, cải tiến quy } \\
\text { trình và giảm tồn kho. }\end{array}$ \\
\hline \multirow{2}{*}{$\begin{array}{l}\checkmark \text { Công ty có thể dễ dàng } \\
\text { theo dõi tình trạng đơn đặt } \\
\text { hàng của công ty (Asamoah } \\
\text { et al., 2016; Devaraj et al., } \\
\text { 2007; Sezen, 2008). }\end{array}$} & \multicolumn{2}{|c|}{$\begin{array}{l}\checkmark \text { Doanh nghiệp có khả năng kiểm soát tình trạng đơn đặt hàng điện tử với một số nhà } \\
\text { cung cấp chính. }\end{array}$} \\
\hline & $\begin{array}{l}\checkmark \text { Tình trạng đơn hàng có thể } \\
\text { theo dõi dễ dàng thông qua hệ } \\
\text { thống mạng nội bộ tập đoàn } \\
\text { và điện thoại, email với các } \\
\text { nhà cung cấp trong nước. }\end{array}$ & $\begin{array}{l}\checkmark \text { Nhà cung cấp phản hồi tình trạng đơn hàng qua điện } \\
\text { thoại và email tương đối nhanh, cung cấp thông tin đáp } \\
\text { ứng được nhu cầu của doanh nghiệp. }\end{array}$ \\
\hline \multirow{2}{*}{$\begin{array}{l}\checkmark \text { Công ty có thể dễ dàng } \\
\text { tìm thấy thông tin về sản } \\
\text { phẩm và giá của các nhà } \\
\text { cung cấp chính (Asamoah } \\
\text { et al., 2016; Boon-itt \& } \\
\text { Wong, 2011; Sezen, 2008) }\end{array}$} & \multicolumn{2}{|c|}{ 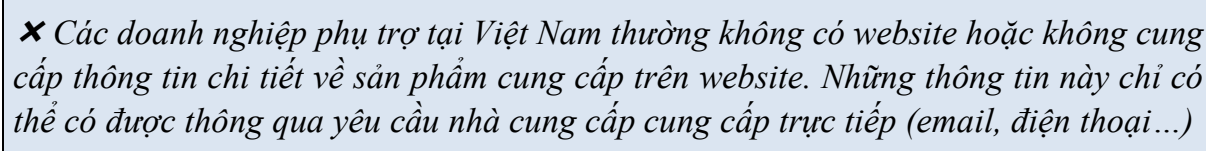 } \\
\hline & $\begin{array}{l}\checkmark \text { Nhà cung cấp đưa ra các } \\
\text { thông tin về giá cả trực tiếp } \\
\text { khi bàn bạc ký hợp đồng. }\end{array}$ & $\begin{array}{l}\checkmark \text { Các thông tin báo giá được bộ phận mua hàng trao } \\
\text { đổi với các nhà cung cấp khi có sự thay đổi về giá cả } \\
\text { nguyên vật liệu. Việc yêu cầu cung cấp bảng báo giá và } \\
\text { bảng vẽ kỹ thuật được nhà cung cấp đáp ứng trong } \\
\text { ngày. Các bộ phận thu mua, cung ứng, lập kế hoạch...sẽ } \\
\text { liên hệ với nhà cung cấp thông qua email. Hình thức } \\
\text { trao đồi trực tiếp giữa hai đối tác giúp đảm bảo tính bảo } \\
\text { mật và dễ dàng trong việc thương lượng, trao đổi. }\end{array}$ \\
\hline
\end{tabular}

Ghi chú: $\checkmark$ Yếu tố được tìm thấy, tương đồng nghiên cứu trước; $\mathbf{X}$ Yếu tố không được tìm thấy ở nghiên cứu trước Nguồn: Kết quả phân tích dữ liệu của nhóm nghiên cứu 


\section{Bảng 2}

Nhóm các yếu tố thuộc thành phần chia sẻ thông tin với khách hàng

\begin{tabular}{|c|c|c|}
\hline Nghiên cứu trước & Công ty A & Công ty $B$ \\
\hline \multirow{2}{*}{$\begin{array}{l}\checkmark \text { Khách hàng chính cung } \\
\text { cấp cho công ty thông tin dự } \\
\text { báo nhu cầu (Asamoah et al., } \\
2016 \text {; Devaraj et al., 2007; } \\
\text { Huo et al., 2014; Sezen, } \\
2008 \text { ) }\end{array}$} & \multicolumn{2}{|c|}{$\begin{array}{l}\checkmark \text { Các công ty quan tâm nhiều đến lợi ích từ thông tin dự báo nhu cầu của khách hàng. } \\
\text { Thông tin dự báo nhu cầu được chia sẻ giữa tất cả các doanh nghiệp trong một tập } \\
\text { đoàn. Các thông tin này giúp doanh nghiệp hoạch định mua hàng và sản xuât hiệu qaa } \\
\text { hơn. }\end{array}$} \\
\hline & $\begin{array}{l}\checkmark \text { Các khách hàng bên ngoài chia sẻ một số } \\
\text { thông tin dự báo thông qua các buồi gặp } \\
\text { mặt giữa các nhà quản lý. }\end{array}$ & $\begin{array}{l}\checkmark \text { Trụ sở chính điều phối hoạt động của } \\
\text { các nhà máy sản xuất tại các nước. Từ } \\
\text { những thông tin dự báo của tổng công ty } \\
\text { và kế hoạch phân bồ sản xuất tới từng } \\
\text { công ty con, các nhà máy tiến hành dự } \\
\text { báo nhu cầu cụ thể hàng quý, hàng tháng. } \\
\text { Tại công ty } \mathrm{B} \text {, dự báo nhu cầu do bộ phận } \\
\text { lập kế hoạch đạm nhận. }\end{array}$ \\
\hline \multirow{2}{*}{$\begin{array}{l}\checkmark \text { Khách hàng chính chia sẻ } \\
\text { cho công ty kế hoạch sản } \\
\text { xuất của họ (Baihaqi \& } \\
\text { Sohal, 2013; Devaraj et al., } \\
\text { 2007; Sezen, 2008) }\end{array}$} & \multicolumn{2}{|c|}{ XKhách hàng thuờng không chia sẻ thông tin kế hoạch sản xuất của họ. } \\
\hline & $\begin{array}{l}\text { xCông ty không quan tâm đến kế hoạch } \\
\text { sán xuất của khách hàng, chì sản xuất theo } \\
\text { đơn hàng gia công. }\end{array}$ & $\begin{array}{l}\text { XHoạt động sản xuất lắp ráp sản phẩm } \\
\text { tại các công ty trong tập đoàn là độc lập. } \\
\text { Các doanh nghiệp tụ kiểm soát lịch trình } \\
\text { sản xuất. }\end{array}$ \\
\hline \multirow{2}{*}{$\begin{array}{l}\checkmark \text { Khách hàng chính có thể } \\
\text { dễ dàng theo dõi tình trạng } \\
\text { đơn đặt hàng của họ } \\
\text { (Asamoah et al., 2016; Huo } \\
\text { et al., 2014; Sezen, 2008; } \\
\text { Zhou \& Benton, 2007) }\end{array}$} & \multicolumn{2}{|c|}{$\begin{array}{l}\checkmark \text { Khách hàng có thể yêu cầu cung cấp các thông tin về tình trạng đơn đặt hàng của } \\
\text { họ bằng cách gọi điện hoặc gửi email. }\end{array}$} \\
\hline & $\begin{array}{l}\checkmark \text { Vào cuối ngày, tất cả các thông tin về số } \\
\text { lượng thành phấm, số lượng khuyết tật, kế } \\
\text { hoạch sản xuất cho ngày tiếp theo sau khi } \\
\text { xem xét tình hình sản xuất được đưa vào hệ } \\
\text { thống sản xuất chung. Khách hàng có thể } \\
\text { chủ động nắm bắt được tình trạng đơn hàng } \\
\text { thông qua dữ liệu sản xuất được cập nhật } \\
\text { hàng ngày trên hệ thống. }\end{array}$ & $\begin{array}{l}\checkmark \text { Tình trạng đơn hàng được theo dõi } \\
\text { bằng cách truy cập vào hệ thống điện tử } \\
\text { của công ty, hoặc yêu cầu bộ phận sản } \\
\text { xuất cung cấp thông tin. Các nhà quản lý } \\
\text { có trách nhiệm thông báo kịp thời tới } \\
\text { khách hàng các vấn đề liên quan đến hoạt } \\
\text { động sản xuất, chất lượng sản phẩm, } \\
\text { cũng như các vấn đề phát sinh có nguy } \\
\text { cơ dần tới tình trạng trễ đơn hàng để } \\
\text { cùng khách hàng phối hợp xử lý. }\end{array}$ \\
\hline $\begin{array}{l}\checkmark \text { Công ty và khách hàng } \\
\text { chính chia sẻ thông tịn } \\
\text { hoạch định năng lực sản xuất } \\
\text { (Asamoah et al., 2016; } \\
\text { Devaraj et al., 2007; Huo et } \\
\text { al., 2014; Sezen, 2008) }\end{array}$ & $\begin{array}{l}\checkmark \text { Do tính chất không thường xuyên và } \\
\text { chiến lược công ty, các thông tin về việc } \\
\text { hoạch định năng lực sản xuất được chia sẻ } \\
\text { trong các cuộc họp lãnh đạo. } \\
\checkmark \text { Do khách hàng chính của công ty A là } \\
\text { công ty mẹ tại Nhật Bản nên việc chia sẻ } \\
\text { thông tin về việc hoạch định năng lực sản } \\
\text { xuất thúc đẩy công ty mẹ có kế hoạch cải } \\
\text { thiện năng lực sản xuất cho công ty A thông } \\
\text { qua các hoạt động đầu tư máy móc, dây } \\
\text { chuyền sản xuât mới, ứng dụng công nghệ } \\
\text { thông tin trong sản xuất... }\end{array}$ & $\begin{array}{l}\checkmark \text { Công ty cung cấp thông tin về tình hình } \\
\text { năng lực sản xuất cho trụ sở chính để có } \\
\text { sự phân bổ sản xuất thích hợp. }\end{array}$ \\
\hline $\begin{array}{l}\checkmark \text { Công ty chia sẻ kế hoạch } \\
\text { sản xuất với khách hàng } \\
\text { chính (Baihaqi \& Sohal, } \\
\text { 2013; Boon-itt \& Wong, } \\
\text { 2011; Flynn et al., 2011) }\end{array}$ & $\begin{array}{l}\checkmark \text { Các công ty con trong tập đoàn (bao gồm } \\
\text { công ty } A \text { ) đều phải chia sẻ thông tin về kế } \\
\text { hoạch sản xuất thông qua hệ thống điện tử } \\
\text { để tất cả các công ty trong tập đoàn có thể } \\
\text { truy cập. }\end{array}$ & $\begin{array}{l}\checkmark \text { Lịch trình sản xuất có thể được quản lý } \\
\text { bởi khách hàng. Nhờ đó, khách hàng } \\
\text { quản lý tốt được hàng tồn kho và kế } \\
\text { hoạch đặt hàng. }\end{array}$ \\
\hline
\end{tabular}

Ghi chú: $\checkmark$ Yếu tố được tìm thấy, tương đồng nghiên cứu trước; $\mathbf{X}$ Yếu tố không được tìm thấy ở nghiên cứu trước

Nguồn: Kết quả phân tích dữ liệu của nhóm nghiên cứu 


\section{Bảng 3}

Nhóm các yếu tố thuộc thành phần chia sẻ thông tin liên chức năng trong doanh nghiệp

\begin{tabular}{|c|c|c|}
\hline Nghiên cứu trước & Công ty A & Công ty B \\
\hline $\begin{array}{l}\checkmark \text { Công ty thường xuyên lưu } \\
\text { hành các báo cáo cung cấp } \\
\text { thông tin về các hoạt động } \\
\text { trong chuỗi cung ứng cho tất } \\
\text { cả các nhà quản lý (Eng, } \\
\text { 2006; Kocoglu et al., 2011; } \\
\text { Martin \& Grbac, 2003) }\end{array}$ & $\begin{array}{l}\checkmark \text { Các báo cáo về mua hàng, đă̆t hàng gia } \\
\text { công, kế hoạch sản xuất, giao } \\
\text { hàng...được gựi đến các trưởng phòng } \\
\text { ban. Một số thông tin chiến lược liên quan } \\
\text { đến khách hàng và nhà cung cấp được } \\
\text { giám đốc và phó giám đốc công ty nắm } \\
\text { giữ. }\end{array}$ & $\begin{array}{l}\checkmark \text { Những thông tin về dự báo xu hướng, } \\
\text { phản hồi của khách hàng, nghiên cứu } \\
\text { nhu cầu khách hàng, phân tích môi } \\
\text { trường cạnh tranh, thông tin tồn kho...là } \\
\text { những thông tin quan trọng trong quắn } \\
\text { lý chuô̂i cung ứng, đều được cung cấp } \\
\text { đến các nhà quản lý bộ phận. Tùy chức } \\
\text { năng từng bộ phận, các nhà quản lý có } \\
\text { những phân tích ảnh hưởng cho từng bộ } \\
\text { phận quản lý của họ. }\end{array}$ \\
\hline \multirow{2}{*}{$\begin{array}{l}\checkmark \text { Các nhà quản lý trong } \\
\text { công ty được cấp quyền truy } \\
\text { cập rộng rãi vào thông tin } \\
\text { quản lý chuỗi cung ưng } \\
\text { (Eng, 2006; Kocoglu et al., } \\
2011 \text { ) }\end{array}$} & \multicolumn{2}{|c|}{ 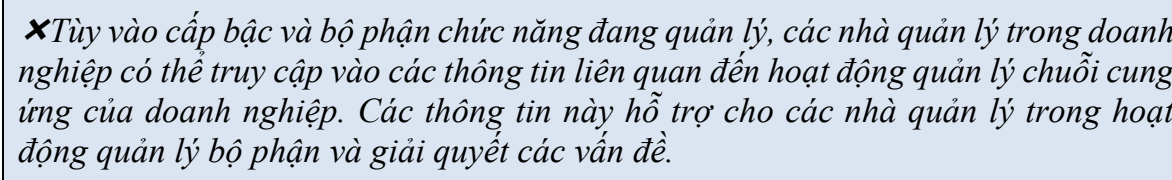 } \\
\hline & $\begin{array}{l}\checkmark \text { Nếu cần những tài liệu nằm ngoài trách } \\
\text { nhiệm, có thể yêu cấu cung cấp thông tin } \\
\text { từ bộ phận đang nắm giữ thông tin. Các } \\
\text { phòng ban có nhiệm vụ đáp ứng thông tin } \\
\text { chính xác và kịp thời. }\end{array}$ & $\begin{array}{l}\checkmark \text { Hệ thống quản lý tài liệu điện tử cho } \\
\text { phép các nhà quản lý truy cập vào các } \\
\text { báo cáo trong quyền hạn chức năng. Các } \\
\text { tài khoản cá nhân khác nhau có các } \\
\text { quyền hạn khác nhau đối với thông tin, } \\
\text { như là chỉ xem, được phép tải về, được } \\
\text { phép chia sẻ, sửa chữa, xóa... }\end{array}$ \\
\hline $\begin{array}{l}\checkmark \text { Các nhà quản lý cấp cao } \\
\text { thường xuyên gặp gỡ nhau } \\
\text { để thảo luận về nhu cầu của } \\
\text { các bộ phận chức năng (Eng, } \\
\text { 2006; Kocoglu et al., 2011; } \\
\text { Martin \& Grbac, 2003) }\end{array}$ & $\begin{array}{l}\checkmark \text { Các cuộc họp ngắn định kỳ hàng tháng } \\
\text { giữa trưởng các phòng ban được tổ chức } \\
\text { để đánh giá hiệu quả hoạt động sản xuất, } \\
\text { xác định các vấn đề và đề ra các giải pháp } \\
\text { khắc phục cũng như hành động phòng } \\
\text { ngừa. Các phòng ban nhận được sự hỗ trợ } \\
\text { giải quyết vấn đề từ các phòng ban khác. }\end{array}$ & $\begin{array}{l}\checkmark \text { Trong các cuộc hộp định kỳ, vấn đề } \\
\text { của các bộ phận chức năng được chia sẻ } \\
\text { với các bộ phận khác để cùng nhau thảo } \\
\text { luận. Nhờ đó, các vấn đề trong các quá } \\
\text { trình được phát hiện và giải quyết kịp } \\
\text { thời, giúp cải thiện hoạt động nội bộ } \\
\text { doanh nghiệp. } \\
\checkmark \text { Khi có những sự cố bất ngờ mà cần có } \\
\text { sự phối hợp giải quê̂́t cua nhiều bộ } \\
\text { phận, cuộc họp triệu tập giữa những nhà } \\
\text { quản lý thuộc các phòng ban liên quan } \\
\text { được thực hiện. }\end{array}$ \\
\hline \multirow{2}{*}{$\begin{array}{l}\checkmark \text { Dữ liệu về sự hài lòng của } \\
\text { khách hàng được phổ biến ở } \\
\text { tất cả các cấp trong công ty } \\
\text { (Eng, 2006; Kocoglu et al., } \\
\text { 2011; Martin \& Grbac, } \\
\text { 2003) }\end{array}$} & \multicolumn{2}{|c|}{$\begin{array}{l}\checkmark \text { Doanh nghiệp quan tâm đến sự không hài lòng và các khiếu nại của khách hàng, } \\
\text { có các hoạt động để nắm bắt nhu cầu khách hàng nhằm cung cấp các sản phẩm đáp } \\
\text { ứng nhu cầu khách hàng tốt hơn. }\end{array}$} \\
\hline & $\begin{array}{l}\text { x Chỉ có các nhà quản lý chịu trách } \\
\text { nhiệm xủ lý nguồn thông tin về sư không } \\
\text { hài lòng của khách hàng. Các thông tin } \\
\text { này it khi được chia sé với công nhân. }\end{array}$ & $\begin{array}{l}\checkmark \text { Tất cả các nhân viên cần biết được } \\
\text { thông tin liên quan đến sự hài lòng của } \\
\text { khách hàng, phù hợp với trách nhiệm } \\
\text { của họ. }\end{array}$ \\
\hline \multirow{2}{*}{$\begin{array}{l}\checkmark \text { Các ý tưởng để nâng cao } \\
\text { sự hài lòng của khách hàng } \\
\text { được chia sẻ công khai ở tất } \\
\text { cả các cấp trong công ty } \\
\text { (Calantone et al., 2002; } \\
\text { Kocoglu et al., 2011; Martin } \\
\& \text { Grbac, 2003) }\end{array}$} & \multicolumn{2}{|c|}{$\begin{array}{l}\checkmark \text { Doanh nghiệp khuyến khích tất cả nhân viên tham gia đóng góp các ý kiến nhằm } \\
\text { cải thiện sự hài lòng khách hàng. } \\
\checkmark \text { Doanh nghiệp có hệ thống xem xét và đánh giá những ý tưởng cải tiến và có những } \\
\text { phần thưởng xứng đáng để góp phần nâng cao tinh thẩn đóng góp ý kiến của tất că } \\
\text { nhân viên. }\end{array}$} \\
\hline & $\begin{array}{l}\checkmark \text { Phần thưởng cho các ý tưởng cải tiến } \\
\text { còn hạn chế, thường là quà tặng hoặc } \\
\text { phiếu mua hàng. }\end{array}$ & $\begin{array}{l}\checkmark \text { Phần thưởng là tiền mặt. Thông tin về } \\
\text { các ý tướng cải tiến được công khai trên } \\
\text { hệ thống quản lý ý tưởng cải tiến } \\
\text { (thường được gọi là hệ thống } \\
\text { "Suggestion"). }\end{array}$ \\
\hline
\end{tabular}




\begin{tabular}{|c|c|c|}
\hline Nghiên cứu trước & Công ty A & Công ty $B$ \\
\hline $\begin{array}{l}\checkmark \text { Khi lập kế hoạch sản phẩm } \\
\text { mới hoă̆c kế hoạch đổi mới } \\
\text { sản phẩm, công ty sứ dụng } \\
\text { cách tiếp cận theo nhóm liên } \\
\text { quan đến tất cả các bộ phận } \\
\text { chức năng (Boon-itt \& } \\
\text { Wong, 2011; Martin \& } \\
\text { Grbac, 2003;) }\end{array}$ & \multicolumn{2}{|c|}{$\begin{array}{l}\checkmark \text { Các nhóm chức năng được thành lập khi cần thiết, thường là để lên kế hoạch cho } \\
\text { việc sản xuất một sản phẩm mới hoặc điều chỉnh sản phẩm theo những yêu cầu của } \\
\text { khách hàng. } \\
\checkmark \text { Sự phối hợp của thành viên thuộc các bộ phận khác nhau thành nhóm liên chức } \\
\text { năng giúp đánh giá vấn đề toàn diện và hố trợ nhau giải quyết vấn đề. }\end{array}$} \\
\hline
\end{tabular}

Ghi chú: $\checkmark$ Yếu tố được tìm thấy, tương đồng nghiên cứu trước; $\mathbf{X}$ Yếu tố không được tìm thấy ở nghiên cứu trước

Nguồn: Kết quả phân tích dữ liệu của nhóm nghiên cứu

\section{Bảng 4}

Nhóm các yếu tố thuộc thành phần chia sẻ kiến thức trong nội bộ doanh nghiệp

\begin{tabular}{|c|c|c|}
\hline Nghiên cứu trước & Công ty A & Công ty $B$ \\
\hline \multirow{2}{*}{$\begin{array}{l}\checkmark \text { Trong công ty, có rất nhiều } \\
\text { cuộc trò chuyện trong nội bộ } \\
\text { giúp duy trì những bài học đã } \\
\text { rút ra trước đây (Calantone } \\
\text { et al., 2002; Eng, 2006; } \\
\text { Kocoglu et al., 2011) }\end{array}$} & \multicolumn{2}{|c|}{$\begin{array}{l}\checkmark \text { Chia sẻ bài học kinh nghiệm được xem là yếu tố cần thiết để lưu giữ thông tin có } \\
\text { giá trị. } \\
\checkmark \text { Các bài học kinh nghiệm được các nhân viên trong doanh nghiệp chia sẻ trong các } \\
\text { cuộc nói chuyện cá nhân, hướng dẫn công việc, các buổi đào tạo hoặc các cuộc họp. }\end{array}$} \\
\hline & $\begin{array}{l}\checkmark \text { Nếu các kiến thức này cũng có ích } \\
\text { với các phòng ban chức năng khác, } \\
\text { có thể đóng góp vào hoạt động vận } \\
\text { hành tốt hơn, trưởng các bộ phận có } \\
\text { thể đề nghị chia sẻ cho các phòng } \\
\text { ban khác thông qua các cuộc họp } \\
\text { ngắn đầu giờ. }\end{array}$ & $\begin{array}{l}\checkmark \text { Bài học kinh nghiệm được thảo luận và chia } \\
\text { sẻ một cách có hệ thống trong nội bộ và giữa } \\
\text { các công ty thành viên. Bên cạnh chia sẻ kiến } \\
\text { thức cá nhân, công ty có những kế hoạch tổ } \\
\text { chức các buối chia sẻ kiến thức do chính các } \\
\text { thành viên trong công ty chủ trì. }\end{array}$ \\
\hline \multirow{2}{*}{$\begin{array}{l}\checkmark \text { Công ty luôn phân tích các } \\
\text { nỗ lực không thành công và } \\
\text { truyền đạt các bài học kinh } \\
\text { nghiệm một cách rộng rãi } \\
\text { (Calantone et al., 2002; } \\
\text { Kocoglu et al., 2011) }\end{array}$} & \multicolumn{2}{|c|}{$\begin{array}{l}\checkmark \text { Những kinh nghiệm từ thực tế công việc, dù có thành công hay thất bại, đều là } \\
\text { những bài học quý giá. Những kiến thức này giúp không ngừng hoàn thiện quy trình } \\
\text { hoạt động của các phòng ban, từ đó nâng cao hiệu quả vận hành chuỗi cung ứng của } \\
\text { doanh nghiệp. }\end{array}$} \\
\hline & $\begin{array}{l}\checkmark \text { Trưởng các bộ phận có thảo luận } \\
\text { các giải pháp đã thực hiện trong các } \\
\text { cuộc họp nội bộ hàng tháng với nhân } \\
\text { viên. }\end{array}$ & $\begin{array}{l}\checkmark \text { Sau khi giải quyết vấn đề, doanh nghiệp } \\
\text { luôn rút kinh nghiệm, về cả sự thành công lẫn } \\
\text { thất bại và được văn bản hóa thành các tài } \\
\text { liệu. Các buồi chia sẻ cách thực hành tốt nhất } \\
\text { (thường được gọi là "Best practice sharing") } \\
\text { được tồ chức thường xuyên cũng là một } \\
\text { phương thức chia sẻ kiến thức mang tính hệ } \\
\text { thống trong các phòng ban. Các bài học này } \\
\text { được truyê̂n đạt đến các cấp nhân viên thuộc } \\
\text { nhiều phòng ban khác nhau trong doanh } \\
\text { nghiệp. }\end{array}$ \\
\hline $\begin{array}{l}\checkmark \text { Công ty có các kế hoạch cụ } \\
\text { thể để chia sẻ bài học kinh } \\
\text { nghiệm trong các hoạt động } \\
\text { tồ chức từ bộ phận này sang } \\
\text { bộ phận khác (Bontis \& } \\
\text { Serenko, 2009; Calantone et } \\
\text { al., 2002;) }\end{array}$ & 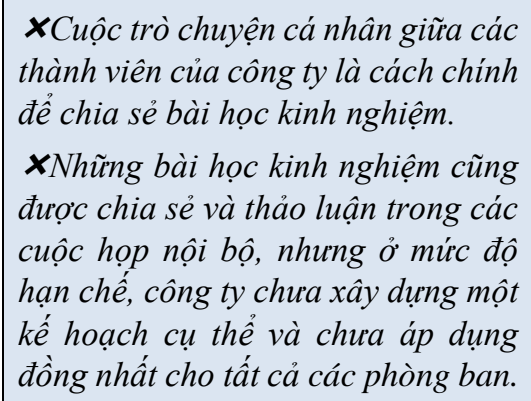 & $\begin{array}{l}\checkmark \text { Các buổi chia sẻ kiến thức nội bộ được lên } \\
\text { kế hoạch và tổ chức thường xuyên bởi bộ } \\
\text { phận đào tạo. Các khóa đào tạo được diễn ra } \\
\text { thường xuyên về các lĩnh vực chyêen môn } \\
\text { làm việc, bảo vệ môi trường, tiêu chuẩn chất } \\
\text { lượng, lao động và việc làm... } \\
\checkmark \text { Các tài liệu đào tạo được cấu trúc lại thường } \\
\text { xuyên một cách có hệ thống và phù hợp để } \\
\text { phân phối cho người học. }\end{array}$ \\
\hline
\end{tabular}




\begin{tabular}{|c|c|c|}
\hline Nghiên cứu trước & Công ty A & Công ty $B$ \\
\hline $\begin{array}{l}\checkmark \text { Quản lý cấp cao liên tục } \\
\text { nhấn mạnh tầm quan trọng } \\
\text { của việc chia sẻ kiến thức } \\
\text { trong công ty (Bontis \& } \\
\text { Serenko, 2009; Calantone et } \\
\text { al., 2002) }\end{array}$ & $\begin{array}{l}\checkmark \text { Đặc điểm doanh nghiệp Nhật Bản } \\
\text { quan tâm đến văn hóa chia sẻ, các } \\
\text { nhà quản lý động viên, khuyến } \\
\text { khích nhân viên tham gia chia sẻ } \\
\text { kiến thức trong doanh nghiệp. }\end{array}$ & $\begin{array}{l}\checkmark \text { Các nhà quản lý có những hướng dẫn, lập } \\
\text { kế hoạch cho các hoạt động chia sẻ kiến thức } \\
\text { trong phòng ban cũng như tiếp nhận kiến thức } \\
\text { từ các phòng ban khác. Họ cũng là người } \\
\text { hướng dẫn cho nhân viên làm thế nào để chia } \\
\text { sẻ kiến thức một cách hiệu quả. }\end{array}$ \\
\hline
\end{tabular}

Ghi chú: $\checkmark$ Yếu tố được tìm thấy, tương đồng nghiên cứu trước; $\mathbf{X}$ Yếu tố không được tìm thấy ở nghiên cứu trước

Nguồn: Kết quả phân tích dữ liệu của nhóm nghiên cứu

\section{Thảo luận kết quả nghiên cứu}

Sau khi phân tích và so sánh kết quả nghiên cứu các thành phần chia sẻ thông tin trong chuỗi cung ứng có tác động tích cực đến hiệu quả chuỗi cung ứng tại hai tình huống doanh nghiệp, công ty $\mathrm{A}$ và công ty $\mathrm{B}$, một số thảo luận chi tiết được trình bày, đồng thời một số nhận định được đúc kết như sau:

Công ty A là một doanh nghiệp hoạt động sản xuất một cách độc lập, nhưng các thông tin vận hành của công ty $\mathrm{A}$ luôn được cập nhật liên tục lên hệ thống điện tử có kết nối với công ty mẹ tại Nhật Bản. Hệ thống này giúp cập nhật kịp thời và bảo mật các thông tin trong hệ thống. Hiện nay, phương thức chính mà công ty $\mathrm{A}$ trao đổi thông tin với các nhà cung cấp là điện thoại và email. Việc phối hợp chia sẻ thông tin với khách hàng, chủ yếu là công ty mẹ, vừa là yêu cầu bắt buộc đối với các doanh nghiệp trong tập đoàn, vừa giúp khách hàng quản lý đặt hàng tốt hơn, đồng thời hỗ trợ doanh nghiệp trong tập đoàn phát triển hoạt động sản xuất. Mạng nội bộ hỗ trợ cho việc chia sẻ thông tin giữa các thành viên trong công ty được dễ dàng và hiệu quả. Bên cạnh đó, việc chia sẻ các ổ đĩa và thư mục máy tính giúp chuyển các thông tin cần thiết đến đúng đối tượng một cách chính xác. Mặt khác, mạng Internet, cụ thể là việc liên lạc qua email giúp chuyển thông tin tới các đối tác bên ngoài một cách kịp thời, cũng như có minh chứng rõ ràng về việc thông tin được chia sẻ.

Công ty $\mathrm{B}$ với số lượng nhà cung cấp lớn và hoạt động sản xuất đa dạng. Việc công ty chia sẻ thông tin với nhà cung cấp chiến lược giúp công ty tối ưu hóa hoạt động quản lý nguồn cung. Cụ thể, kế hoạch sản xuất được chia sẻ định kỳ với các nhà cung cấp giúp rút ngắn thời gian đặt nguyên vật liệu. Trên cơ sở thông tin nhận được, các nhà cung cấp tính toán số lượng cần cung ứng và tự điều chỉnh hoạt động sản xuất để đảm bảo giao hàng đúng hạn. Bên cạnh đó, hệ thống thông tin của công ty giúp các nhà quản lý tìm kiếm những thông tin hỗ trợ cho hoạt động quản lý chuỗi cung ứng, ví dụ như thông tin đặt hàng, kế hoạch sản xuất, hoạt động giao hàng, sự hài lòng của khách hàng...Đồng thời, việc trao đổi thông tin điện tử chính xác và kịp thời giúp củng cố mối quan hệ hợp tác của các doanh nghiệp trong chuỗi cung ứng. Mặt khác, đối với dòng thông tin trong nội bộ, tùy theo trách nhiệm công việc, tất cả nhân viên đều có thể truy xuất được các thông tin có liên quan, ví dụ như, nhân viên đều nhận thông tin về sự không hài lòng của khách hàng, từ đó tìm kiếm các giải pháp đáp ứng tốt hơn những yêu cầu khách hàng. Các thông tin được văn bản hóa và quản lý trong hệ thống tài liệu điện tử giúp cho việc truy cập thông tin nhanh chóng, đồng bộ và tránh những sai lệch khi chuyển giao thông tin nhiều lần. Thêm vào đó, công ty thực hiện trao đổi kiến thức thông qua các cuộc họp nội bộ trong từng phòng ban và giữa các phòng ban với nhau; từ đó lập kế hoạch cụ thể cho các lớp tập huấn nội bộ về những bài học cũng như những kiến thức đúc kết được từ thực tế làm việc của các thành viên trong công ty.

Nhìn chung, cả hai doanh nghiệp đều quan tâm đến quản lý việc chia sẻ thông tin hiệu quả trong chuỗi cung ứng để phối hợp, tận dụng các nguồn lực bên trong và bên ngoài doanh nghiệp. Cả 
hai doanh nghiệp đều nhận định rằng việc chia sẻ thông tin với các nhà cung cấp nguyên vật liệu, linh kiện, chi tiết chiến lược có ảnh hưởng nhiều đến hiệu quả chuỗi cung ứng; trong khi đó, việc chia sẻ thông tin với nhà cung cấp về các nguyên vật liệu, linh kiện, chi tiết thường thì không đóng góp nhiều cho hoạt động vận hành chuỗi cung ứng của doanh nghiệp. Chia sẻ thông tin vận hành thường xuyên với khách hàng giúp các doanh nghiệp tự điều chỉnh kế hoạch sản xuất và thay đổi cần thiết trong thiết kế sản phẩm nhằm đáp ứng kịp thời với yêu cầu thay đổi từ khách hàng. Bên cạnh đó, việc chia sẻ thông tin trong nội bộ là một yêu cầu bắt buộc trong việc giải quyết vấn đề của từng bộ phận ở cả hai doanh nghiệp tình huống này. Sự phối hợp hiệu quả giữa các phòng ban dựa vào các thông tin được chia sẻ lẫn nhau giúp rút ngắn thời gian phản hồi khách hàng. Ngoài ra, đối với các vấn đề liên quan đến trách nhiệm của nhiều bộ phận, các nhóm liên chức năng được hình thành. Hoạt động của các nhóm liên chức năng không chỉ giúp quá trình ra quyết định nhanh và chính xác hơn, mà còn giúp bổ sung các kiến thức và kỹ năng thuộc các nhóm chuyên môn khác nhau, đồng thời thúc đẩy việc học tập trong nhóm. Đặc biệt, từ kinh nghiệm thực tiễn quản lý chuỗi cung ứng của hai doanh nghiệp điện tử điển hình tại Việt Nam, để phát huy vai trò của việc chia sẻ thông tin trong chuỗi cung ứng, một số yếu tố, như là quy mô doanh nghiệp, hệ thống quản trị, hạ tầng công nghệ thông tin...cũng được nhận thấy là có ảnh hưởng khác nhau lên hiệu quả chuỗi cung ứng. Vì vậy, các doanh nghiệp điện tử cần chú trọng xây dựng và phát triển chuỗi cung ứng thông qua các hoạt động sau:

\subsection{Tăng cuờng chia sẻ thông tin với nhà cung cấp giúp cải thiện hiệu quả chuỗi cung úng điện tủ̉}

Thực tế quan sát cho thấy các nhà cung cấp thường không cung cấp độc quyền cho một khách hàng duy nhất; những mối quan hệ hợp tác không chặt chẽ dễ gây nên tình trạng thiếu hụt nguyên vật liệu. Thông tin dự báo nhu cầu chia sẻ với nhà cung cấp không chỉ có lợi cho nhà cung cấp, mà còn giảm nguy cơ thiếu hụt nguyên vật liệu cho doanh nghiệp. Dựa theo kết quả nghiên cứu này, các doanh nghiệp điện tử Việt Nam đã nhận thức được vai trò của chia sẻ thông tin vận hành đến nhà cung cấp. Cụ thể, thông tin dự báo nhu cầu được các doanh nghiệp chia sẻ với các nhà cung cấp chính để giúp các nhà cung cấp tăng cường độ chính xác của kế hoạch sản xuất, giảm sự không chắc chắn trong nhu cầu; điều này phù hợp với nghiên cứu của Baihaqi và Sohal (2013) và nghiên cứu của Chatzoudes và Chatzoglou (2015). Tuy nhiên, nghiên cứu của Huo và cộng sự (2014) cho rằng việc chia sẻ kế hoạch sản xuất với nhà cung cấp không đem lại lợi ích đáng kể cho doanh nghiệp, trong khi các nghiên cứu của Kocoglu và cộng sự (2011) và nghiên cứu của Asamoah và cộng sự (2016) lại khẳng định ngược lại. Kết quả nghiên cứu hai tình huống doanh nghiệp điện tử điển hình tại Việt Nam cho thấy rằng đối với doanh nghiệp lắp rắp với quy mô lớn, số lượng nhà cung cấp nhiều, việc chia sẻ kế hoạch sản xuất với nhà cung cấp chiến lược giúp tiết kiệm nỗ lực cho hoạt động quản lý nguồn cung, đồng thời giúp nhà cung cấp chủ động xây dựng kế hoạch sản xuất và giao hàng kịp thời. Thông tin về kế hoạch sản xuất không chỉ giúp doanh nghiệp tiết kiệm thời gian và nỗ lực trong việc tính toán lượng đặt hàng nguyên vật liệu tối ưu, mà còn giúp các nhà cung cấp chủ động trong việc lập kế hoạch sản xuất. Ngoài ra, chia sẻ thông tin về năng lực sản xuất giữa doanh nghiệp và nhà cung cấp giúp các doanh nghiệp có những hoạt động hỗ trợ nhằm nâng cao khả năng cung ứng, từ đó sẽ cải thiện mối quan hệ hợp tác. Kết quả nghiên cứu ở khía cạnh này ủng hộ kết quả nghiên cứu của Barratt và Barratt (2011) và nghiên cứu của Kembro và Selviaridis (2015).

Tiếp theo, về phương thức theo dõi đơn hàng của công ty, kết quả nghiên cứu cho thấy công ty chủ yếu sử dụng điện thoại, email và hệ thống dữ liệu điện tử để cập nhật những thông tin về tình trạng đơn hàng, như là đã hoàn tất, đã được vận chuyển, còn lưu kho, hay sẽ được chuyển giao đúng hạn/trễ hạn. Kết quả tìm thấy này có sự tương đồng với nghiên cứu của Kembro và Selviaridis (2015) và nghiên cứu của Wang, Pfohl, Berbner, và Keck (2016). Tuy nhiên, thay vì thông tin về đặc tính và thiết kế sản phẩm cho đơn hàng đó được công khai trên website của nhà 
cung cấp, cho phép các công ty truy cập dễ dàng như trong nghiên cứu của Boon-itt và Wong (2011), kết quả nghiên cứu này cho thấy đối với doanh nghiệp tại Việt Nam, thông tin về sản phẩm cũng như thông tin về giá được trao đổi trực tiếp với các nhà cung cấp thông qua điện thoại và email. Thực chất là do các doanh nghiệp phụ trợ tại Việt Nam thường không có website hoặc không muốn cung cấp thông tin chi tiết về sản phẩm cung cấp trên website. Hơn nữa, chất lượng và giá cả ảnh hưởng đáng kể đến quyết định lựa chọn và hợp tác với nhà cung cấp. Các nhà cung cấp có trách nhiệm cung cấp những thông tin này nhanh chóng và chính xác đến với khách hàng.

Do đó, các doanh nghiệp cần quan tâm đến mối quan hệ với các nhà cung cấp trong chuỗi cung ứng. Sự hợp tác trong việc chia sẻ thông tin giúp các doanh nghiệp chủ động hơn trong việc lập kế hoạch sản xuất kinh doanh, đồng thời có các chiến lược phối hợp thích hợp với nhà cung cấp nhằm quản lý hiệu quả các hoạt động trong chuỗi cung ứng. Sự tin tưởng và cam kết đóng vai trò quan trọng trong việc xây dựng và phát triển mối quan hệ tốt giữa các bên liên quan; điều này tạo điều kiện thuận lợi cho việc chia sẻ thông tin ở mức độ cao hơn với chất lượng thông tin tốt. Ngoài ra, chia sẻ thông tin giúp giảm sự không chắc chắn, vì vậy việc chú trọng vào xây dựng và duy trì mối quan hệ tốt với các nhà cung cấp trong chuỗi cung ứng là rất cần thiết đối với doanh nghiệp điện tử Việt Nam nhằm giúp trao đổi thông tin dễ dàng và hiệu quả.

\subsection{Tăng cuờng chia sẻ thông tin với khách hàng giúp cải thiện hiệu quả chuỗi cung úng điện tü̉}

Hiện tại, các doanh nghiệp trong chuỗi cung ứng điện tử tại Việt Nam thường là các doanh nghiệp sản xuất chi tiết, lắp láp linh kiện điện tử. Khách hàng chính của các doanh nghiệp này thường là công ty mẹ - những tập đoàn có vốn đầu tư nước ngoài lớn. Dựa theo kết quả nghiên cứu tình huống, các thông tin dự báo nhu cầu, năng lực sản xuất hay tình trạng đơn hàng được chia sẻ tới các khách hàng chính. Sự thay đổi về năng lực sản xuất của một doanh nghiệp ảnh hưởng nhiều đến các đối tác kinh doanh trong chuỗi cung ứng. Sự không chắc chắn về nhu cầu khách hàng khiến cho các doanh nghiệp gặp nhiều khó khăn trong việc hoạch định sản xuất. Những thông tin dự báo nhu cầu từ khách hàng là nguồn dữ liệu quý giá cho hoạt động hoạch định tại doanh nghiệp, là cơ sở quan trọng để doanh nghiệp thiết lập lịch trình sản xuất, chủ động trong hoạt động với các nhà cung cấp và điều phối nguồn lực hiệu quả. Cụ thể, thông tin dự báo nhu cầu của khách hàng giúp công ty có sự chủ động và chuẩn bị tốt cho kế hoạch đặt hàng nguyên vật liệu và kế hoạch sản xuất, giúp giảm tỷ lệ giao hàng trễ cho khách hàng. Bên cạnh đó, các thông tin được cung cấp bởi khách hàng có vai trò quan trọng trong việc nâng cao tính linh hoạt của chuỗi cung ứng trước những sự không chắc chắn từ môi trường kinh doanh. Kết quả nghiên cứu tìm thấy ở khía cạnh này ủng hộ một số nghiên cứu định tính trước có liên quan, điển hình là nghiên cứu của Barratt và Barratt (2011), nghiên cứu của Kembro và Selviaridis (2015) và nghiên cứu của Wang và cộng sự (2016). Thêm vào đó, do đặc điểm của hai doanh nghiệp nghiên cứu là thành viên của tập đoàn, khách hàng chính của công ty là công ty mẹ của tập đoàn; cho nên kế hoạch sản xuất của công ty được chia sẻ với khách hàng là yêu cầu bắt buộc. Chia sẻ thông tin giúp mối quan hệ hợp tác với các khách hàng vượt qua khoảng cách thời gian, địa lý; cũng như giúp các đối tác cùng nhau chia sẻ rủi ro và sự không chắc chắn, có được cái nhìn chính xác và toàn diện về yêu cầu và mong muốn của nhau. Các khách hàng có quyền theo dõi tình trạng đơn đặt hàng của họ. Nhờ cung cấp những thông tin này cho khách hàng, doanh nghiệp có thể cải thiện được sự hài lòng và tin cậy đối với dịch vụ của doanh nghiệp. Đồng thời, khách hàng quản lý tốt được hàng tồn kho và có kế hoạch đặt hàng phù hợp. Điều kiện ràng buộc này là một bổ sung cho nghiên cứu của Flynn và cộng sự (2011), nghiên cứu của Baihaqi và Sohal (2013) và nghiên cứu của Huo và cộng sự (2014).

Mặt khác, một số nghiên cứu, điển hình là nghiên cứu của Sezen (2008) và nghiên cứu của 
Baihaqi và Sohal (2013) đã nhấn mạnh việc sử dụng thông tin kế hoạch sản xuất của khách hàng giúp sắp xếp lịch trình sản xuất linh hoạt từ đó cải thiện hiệu quả vận hành của doanh nghiệp. Tuy nhiên, trong thực tế, doanh nghiệp điện tử Việt Nam không nhận được kế hoạch sản xuất của khách hàng, do chỉ là doanh nghiệp sản xuất chi tiết và lắp ráp linh kiện. Khách hàng chính có thể theo dõi tình trạng sản xuất đơn hàng dễ dàng trên hệ thống, qua điện thoại hoặc email. Điều này giúp cho khách hàng hoạch định sản xuất, phân phối hiệu quả và cải thiện tính minh bạch trên toàn chuỗi cung ứng. Kết quả này hỗ trợ cho kết luận trong nghiên cứu của Wang và cộng sự (2016) và nghiên cứu của Asamoah và cộng sự (2016).

Cuối cùng, tương tự với nghiên cứu của Kocoglu và cộng sự (2011) và nghiên cứu của Kembro và Selviaridis (2015), việc chia sẻ thông tin mang tính chiến lược như năng lực sản xuất giúp tăng cường sự hỗ trợ lẫn nhau trong kế hoạch đặt hàng, hoạch định cho sự thay đổi cho cả doanh nghiệp và khách hàng của doanh nghiệp, đảm bảo thỏa mãn nhu cầu khách hàng, và duy trì mối quan hệ hợp tác lâu dài.

\subsection{Tăng cuờng chia sẻ thông tin giữa các bộ phận chức năng trong doanh nghiệp giứp cải thiện hiệu quả chuỗi cung úng điện tủ̉}

Trong thực tiễn quản lý doanh nghiệp, các nhà quản lý cần được cung cấp đầy đủ, chính xác thông tin hỗ trợ cho hoạt động quản lý. Thông tin trao đổi giữa những trưởng bộ phận mang tính chiến lược đối với hoạt động vận hành của doanh nghiệp. Theo kết quả nghiên cứu hai tình huống doanh nghiệp điển hình, việc chia sẻ thông tin trong nội bộ và sự phối hợp hiệu quả giữa các phòng ban là một yêu cầu bắt buộc nhằm rút ngắn thời gian phản hồi khách hàng. Các báo cáo liên quan đến hoạt động quản lý chuỗi cung ứng được chia sẻ tới các cấp quản lý doanh nghiệp, giúp các nhà quản lý ở các bộ phận khác nhau có cái nhìn toàn diện và chính xác hơn. Nhờ vào việc nắm bắt được những thông tin từ những bộ phận chức năng khác nhau, các nhà quản lý có những sự hỗ trợ phù hợp, đồng thời có dữ liệu cho việc đánh giá những rủi ro có thể xảy ra liên quan đến bộ phận đang quản lý. Theo đó, một khi việc chia sẻ thông tin giữa các phòng ban trong một doanh nghiệp được thực hiện một cách hiệu quả, các nhà quản lý có thể phối hợp với các đối tác trong chuỗi cung ứng nhanh chóng, hiệu quả hơn. Kết quả nghiên cứu ở khía cạnh này ủng hộ kết quả nghiên cứu của Martin và Grbac (2003) và nghiên cứu của Eng (2006). Đặc biệt, nghiên cứu này tìm thấy có giới hạn truy cập của các nhà quản lý doanh nghiệp vào thông tin quản lý chuỗi cung ứng theo cấp bậc và theo bộ phận chức năng có liên quan; điều này bổ sung vào kết quả nghiên cứu của Kocoglu và cộng sự (2011) về tác động tích cực của khả năng tiếp cận các tài liệu chia sẻ giữa các bộ phận chức năng đối với các quản lý doanh nghiệp. Bên cạnh đó, tương đồng với nghiên cứu của Eng (2006) và nghiên cứu của Asamoah và cộng sự (2016), nghiên cứu này cũng tìm thấy rằng các cuộc gặp gỡ giữa những nhà quản lý trong doanh nghiệp nhằm thảo luận những vấn đề phát sinh trong hoạt động vận hành sẽ giúp cải thiện hiệu quả vận hành doanh nghiệp. Những thông tin về những lời phàn nàn của khách hàng được chia sẻ với nhân viên trong công ty phù hợp với cấp bậc và quyền hạn của họ. Các thành viên trong doanh nghiệp đều phải có trách nhiệm trong công việc để tạo ra sản phẩm đáp ứng đầy đủ những yêu cầu từ khách hàng. Họ cần biết được những sự không hài lòng của khách hàng, theo mức độ phù hợp với trách nhiệm của họ. Kết quả tìm thấy ở khía cạnh này cũng góp phần bổ sung vào kết quả nghiên cứu của Kocoglu và cộng sự (2011).

Đồng thời, các hoạt động cải tiến cần được thông tin đến toàn bộ các cấp nhân viên vì đây là động lực để nhân viên tự phát triển, là cơ hội để nhân viên đóng góp nhằm nâng cao năng suất lao động của cá nhân và hiệu quả hoạt động tại doanh nghiệp. Tương tự với kết quả nghiên cứu của Martin và Grbac (2003) và nghiên cứu của Eng (2006), nghiên cứu này cũng nhấn mạnh tầm quan trọng của toàn thể nhân viên trong công ty tham gia đóng góp ý kiến nhằm nâng cao hiệu quả 
công việc, giúp doanh nghiệp nhìn vấn đề từ nhiều góc nhìn khác nhau, đồng thời gia tăng sự gắn bó và trách nhiệm của nhân viên trong công việc.

Bên cạnh đó, việc phát triển và sản xuất một sản phẩm yêu cầu sự hợp tác từ nhiều lĩnh vực khác nhau, điển hình là bộ phận $\mathrm{R} \& \mathrm{D}$, tiếp thị, thiết kế, kỹ thuật...nên các nhóm làm việc liên chức năng thường được thành lập, bao gồm thành viên có nhiều chuyên môn khác nhau để giải quyết những vấn đề, những dự án cải tiến trong thời hạn nhất định. Kết quả nghiên cứu ở khía cạnh này bổ sung vào nghiên cứu của Kocoglu và cộng sự (2011) và Asamoah và cộng sự (2016). Việc kết hợp nguồn lực từ các phòng ban giúp tiếp cận nhiều nguồn thông tin và tiếp cận cách giải quyết vấn đề từ nhiều cá nhân khác nhau. Bên cạnh đó, nhờ vào việc trao đổi thông tin hiệu quả giữa các phòng ban, các thông tin cần thiết cho việc giải quyết vấn đề được hỗ trợ. Các bộ phận chức năng phối hợp làm việc với nhau hướng đến mục đích chung là đáp ứng yêu cầu, phản ứng tốt trước những sự thay đổi từ khách hàng và cải thiện mức độ dịch vụ khách hàng.

Vì vậy, các nhà quản lý doanh nghiệp cần xây dựng và duy trì kênh trao đổi thông tin hiệu quả. Phương thức trao đổi thông tin tùy theo dạng thức thông tin và sự đánh giá về chất lượng thông tin của đối tượng tiếp nhận thông tin. Việc chia sẻ thông tin điện tử qua mạng nội bộ hoặc internet giúp hạn chế những sai sót trong việc tiếp nhận thông tin liên quan đến yếu tố con người, đồng thời thông tin được chuyển tới các thành viên trong công ty cũng như đối tác bên ngoài kịp thời và có thể truy xuất nguồn gốc thông tin.

\subsection{Tăng cuờng chia sẻ kiến thức trong nội bộ doanh nghiệp giúp cải thiện hiệu quả chuỗi cung úng điện tü̉}

Kết quả nghiên cứu chỉ ra rằng, các doanh nghiệp điện tử ngày càng quan tâm đến quản lý kiến thức, trong đó chia sẻ kiến thức giúp cải thiện phương thức làm việc và kết quả của từng cá nhân. Tương tự với kết quả nghiên cứu của Calantone và cộng sự (2002), các doanh nghiệp điện tử Việt Nam cũng chú trọng nhiều đến việc chia sẻ bài học kinh nghiệm trong nội bộ. Chính những vấn đề phát sinh trong quá khứ là bài học kinh nghiệm quý giá nhằm ngăn chặn sự việc tái diễn trong tương lai. Chia sẻ cách giải quyết những vấn đề này giúp những cá nhân trong cùng một bộ phận và giữa những bộ phận với nhau đúc kêt những phương pháp tiếp cận và xử lý tốt hơn cho các vấn đề phát sinh trong tương lai. Đặc biệt, qua quá trình trao đổi trực tiếp, tri thức ẩn của các cá nhân được chia sẻ và nắm bắt bởi nhiều thành viên trong doanh nghiệp, điều này đóng góp lớn cho hoạt động quản trị tri thức.

Bên cạnh đó, kết quả nghiên cứu này cũng chỉ ra rằng việc xây dựng văn hóa chia sẻ kinh nghiệm giải quyết vấn đề trong toàn thể doanh nghiệp là rất quan trọng. Văn hóa chia sẻ giúp nhân viên từ các bộ phận khác nhau có phản ứng thích hợp trong các vấn đề phát sinh trong quá trình vận hành doanh nghiệp. Khía cạnh này chưa được xét đến trong nghiên cứu của Kembro và Selviaridis (2015) và nghiên cứu của Wang và cộng sự (2016). Thêm vào đó, nghiên cứu của Asamoah và cộng sự (2016) đã đưa ra kết luận rằng việc chia sẻ các bài học một cách cá nhân có thể không mang lại hiệu quả cũng như dẫn đến những sai lầm. Tuy nhiên, kết quả từ nghiên cứu hai tình huống doanh nghiệp điện tử điển hình tại Việt Nam cho thấy không phải công ty nào cũng có kế hoạch cụ thể hay nguồn tài liệu có giá trị để chia sẻ bài học kinh nghiệm từ bộ phận này sang bộ phận khác mà chủ yếu vẫn dựa vào giao tiếp cá nhân. Và yếu tố quan trọng nhất kích hoạt các hoạt động chia sẻ kiến thức nội bộ chính là sự quan tâm của nhà quản lý. Nhà quản lý là người hiểu rõ nhất lợi ích của việc chia sẻ thông tin và kiến thức, trong nội bộ và bên ngoài; từ đó khuyến khích và hỗ trợ nhân viên chia sẻ bài học kinh nghiệm, dù là bài học thành công hay thất bại. Cũng do nhấn mạnh tầm quan trọng của việc chia sẻ kiến thức nội bộ trong tổ chức, các nhà quản lý cấp cao ở cả hai doanh nghiệp nghiên cứu tình huống là những người trực tiếp lên kế hoạch cụ thể và cũng chính là người hướng dẫn cho các hoạt động chia sẻ kiến thức nội bộ. Đồng thời, các nhà 
quản lý động viên nhân viên làm việc theo nhóm, có những kế hoạch cụ thể nhằm tăng cường sự hợp tác với các phòng ban chức năng khác, và xây dựng cơ chế phù hợp để chia sẻ kiến thức và truyền đạt các bài học kinh nghiệm trong toàn công ty. Kết quả nghiên cứu ở khía cạnh này ủng hộ kết quả nghiên cứu của Kocoglu và cộng sự (2011) và nghiên cứu của Asamoah và cộng sự (2016).

Vì vậy, chia sẻ kiến thức đóng vai trò quan trọng trong việc duy trì và cải thiện hoạt động vận hành của doanh nghiệp. Việc xây dựng và duy trì kiến thức nội bộ giúp tăng khả năng xử lý của nhân viên trước những tình huống phức tạp. Tất cả mọi cá nhân trong doanh nghiệp cần phải hiểu và có ý thức chủ động trong việc chia sẻ kiến thức và tiếp nhận kiến thức từ người khác. Thêm vào đó, không chỉ thu thập kiến thức một cách rời rạc bởi từng cá nhân, các doanh nghiệp cần có kế hoạch, cơ chế thích hợp để hệ thống hóa, tích luỹ và chia sẻ đồng bộ kiến thức cho toàn thể thành viên trong công ty.

Một cách tổng quát, để cải thiện hiệu quả chuỗi cung ứng điện tử, bên cạnh việc tăng cường các thành phần chia sẻ thông tin trong chuỗi như thảo luận trên, vấn đề chất lượng thông tin chia sẻ cũng cần được đặc biệt quan tâm. Trong bối cảnh cạnh tranh như ngày nay, việc bảo mật thông tin là rất quan trọng. Các thông tin được chia sẻ với một đối tác cần phải đảm bảo được bảo mật đối với bên thứ ba. Cam kết giữa hai bên cần phải rõ ràng và chặt chẽ để tránh việc bị tiết lộ những thông tin mang tính chiến lược. Chia sẻ thông tin kịp thời giúp đưa ra những tín hiệu nhanh chóng cho đối tượng nhận được thông tin này trong việc giải quyết các vấn đề có liên quan. Các thông tin dự báo nhu cầu không chính xác gây nên hiệu ứng Bull-whip, ảnh hưởng đến toàn bộ chuỗi cung ứng. Việc chia sẻ thông tin cần phải được chọn lọc những thông tin cần thiết cho vấn đề mà đối tượng yêu cầu thông tin quan tâm, tránh lãng phí công sức xử lý thông tin cho cả hai bên. Bên cạnh đó, thông tin được chia sẻ với mức độ cao nhưng không đảm bảo được các yêu cầu về chất lượng, cũng như thông tin bị chậm trễ, không chính xác, hay không đầy đủ...sẽ không mang lại giá trị sử dụng cho người nhận được thông tin. Quản lý chất lượng thông tin là một quá trình liên tục và đòi hỏi sự phối hợp của nhiều thành phần trong chuỗi cung ứng. Các tiêu chí để đánh giá chất lượng thông tin và thang điểm cho các tiêu chí này là khác nhau giữa các doanh nghiệp. Vì vậy, các doanh nghiệp nên tìm hiểu các yêu cầu về chất lượng thông tin từ các đối tác trực tiếp, cần định nghĩa, đánh giá và có những giải pháp để nâng cao chất lượng thông tin được chia sẻ với các thành viên trong chuỗi cung ứng.

\section{Kết luận}

Nhìn chung, nghiên cứu này đã nhận diện được các thành phần chia sẻ thông tin trong chuỗi cung ứng có ảnh hưởng đến hiệu quả chuỗi cung ứng của các doanh nghiệp điện tử tại Việt Nam, phân tích tác động của các thành phần này và thảo luận một số hàm ý quản trị tương ứng. Cụ thể, thông qua nghiên cứu tình huống thực tế tại hai doanh nghiệp điện tử điển hình tại Việt Nam, nghiên cứu này đã phân tích, so sánh và tổng kết được bốn thành phần chính của chia sẻ thông tin trong chuỗi cung ứng có tác động đến hiệu quả chuỗi cung ứng điện tử tại Việt Nam:

- Chia sẻ thông tin với nhà cung cấp, bao gồm các thông tin được trao đổi giữa công ty với các nhà cung cấp chính như là thông tin dự báo nhu cầu, kế hoạch sản xuất, năng lực sản xuất, tình trạng đơn hàng, thông tin về đặc điểm sản phẩm và giá cả từ nhà cung cấp;

- Chia sẻ thông tin với khách hàng, bao gồm các thông tin được trao đổi giữa công ty với các khách hàng chính như là thông tin dự báo nhu cầu, kế hoạch sản xuất, năng lực sản xuất, tình trạng đơn hàng;

- Chia sẻ thông tin liên chức năng, bao gồm cung cấp các báo cáo liên quan đến hoạt động quản trị chuỗi cung ứng, khả năng truy cập rộng rãi thông tin quản lý chuỗi cung ứng của các nhà 
quản lý, các cuộc thảo luận của các nhà quản lý về nhu cầu của các bộ phận chức năng, dữ liệu về sự hài lòng của khách hàng được phổ biến ở tất cả các cấp, ý tưởng để nâng cao sự hài lòng của khách hàng được chia sẻ công khai, sử dụng cách tiếp cận theo nhóm liên quan đến tất cả các bộ phận chức năng khi lập kế hoạch sản phẩm mới hoặc kế hoạch đổi mới sản phẩm;

- Chia sẻ kiến thức trong nội bộ doanh nghiệp, liên quan đến việc công ty có nhiều cuộc trò chuyện trong nội bộ giúp duy trì những bài học, phân tích các nỗ lực thành công/không thành công và truyền đạt các bài học kinh nghiệm một cách rộng rãi, có các kế hoạch cụ thể để chia sẻ bài học kinh nghiệm trong các hoạt động tổ chức từ bộ phận này sang bộ phận khác, và các nhà quản lý cấp cao liên tục nhấn mạnh tầm quan trọng của việc chia sẻ kiến thức trong công ty.

Theo đó, nghiên cứu này khái quát hàm ý quản trị cho từng nhóm đối tượng khác nhau cũng như một số hướng mở rộng nghiên cứu trong lĩnh vực này, như sau:

Trước tiên, để nâng cao hiệu quả hoạt động chia sẻ thông tin nhằm mục đích cải thiện hiệu quả chuỗi cung ứng điện tử, các doanh nghiệp trong chuỗi cung ứng điện tử tại Việt Nam cần đặc biệt quan tâm đến hai vấn đề sau: (a) mối quan hệ hợp tác tốt giữa các đối tác trong chuỗi giúp đảm bảo hoạt động chia sẻ thông tin thường xuyên và với mức độ chất lượng thông tin cao. Các doanh nghiệp cần chú trọng vào việc xây dựng mối quan hệ hợp tác bền vững và đáng tin cậy với các đối tác trong chuỗi cung ứng, đặc biệt là những nhà cung cấp và khách hàng chiến lược. Sự tin tưởng giúp các doanh nghiệp sẵn sàng chia sẻ các thông tin mang tính chiến lược, cung cấp quyền truy cập cho các nhà cung cấp chính vào một số thông tin phù hợp trong hệ thống quản lý của doanh nghiệp, giúp rút ngắn thời gian và nỗ lực trong quá trình cung ứng của doanh nghiệp; (b) nhà quản lý doanh nghiệp đóng vai trò rất quan trọng trong việc thúc đẩy chia sẻ thông tin hiệu quả trong chuỗi cung ứng. Nhà quản lý cần hiểu được lợi ích của việc chia sẻ thông tin và kiến thức, trong nội bộ và bên ngoài, đồng thời khuyến khích và hỗ trợ nhân viên chia sẻ bài học kinh nghiệm, dù là bài học thành công hay thất bại. Các nhà quản lý có thể động viên nhân viên làm việc theo nhóm, có những kế hoạch cụ thể nhằm tăng cường sự hợp tác với các phòng ban chức năng khác, xây dựng cơ chế phù hợp để chia sẻ thông tin và truyền đạt các bài học kinh nghiệm một cách đồng bộ trong toàn bộ tổ chức.

Tiếp theo, các doanh nghiệp thuộc các ngành sản xuất khác có thể tham khảo kết quả nghiên cứu này để có thêm những thông tin về tầm quan trọng và thực tế sử dụng hiệu quả thông tin trong việc cải thiện hiệu quả hoạt động quản lý chuỗi cung ứng. Dòng thông tin trong chuỗi cung ứng đóng vai trò quan trọng và việc chia sẻ thông tin trong chuỗi cung ứng là một yêu cầu cần thiết. Việc nhận diện được tầm quan trọng và các thành phần chia sẻ thông tin trong chuỗi cung ứng giúp doanh nghiệp có những kế hoạch phù hợp để cải thiện dòng thông tin trong chuỗi cung ứng, từ đó nâng cao hiệu quả hoạt động chuỗi cung ứng của doanh nghiệp.

Cuối cùng, các nhà nghiên cứu quan tâm đến lĩnh vực nghiên cứu này có thêm sự hiểu biết về các thành phần chia sẻ thông tin trong chuỗi cung ứng điện tử từ thực tiễn các doanh nghiệp điển hình trong một ngành, cụ thể là doanh nghiệp lắp ráp. Việc nghiên cứu các thành phần chia sẻ thông tin trong chuỗi cung ứng ở ngành cụ thể giúp cho các doanh nghiệp trong chuỗi cung ứng của ngành đó có được những thông tin chi tiết nhằm hỗ trợ cho hoạt động quản trị chuỗi cung ứng hiệu quả. Tuy nhiên, dòng thông tin không chỉ quan trọng trong chuỗi cung ứng điện tử mà còn đối với tất cả các chuỗi cung ứng khác. Việc thực hiện nghiên cứu trên lĩnh vực khác như dịch vụ, xây dựng, y tế... nên được xem xét. Hơn nữa, bên cạnh bổ sung vào khoảng trống nghiên cứu hiện hành cho một số nghiên cứu định tính về tác động của chia sẻ thông tin và kiến thức trong nội bộ doanh nghiệp, ví dụ như các nghiên cứu của Barratt và Barratt (2011), Kembro và Selviaridis (2015), Wang và cộng sự (2016)...nghiên cứu này mở ra một số hướng nghiên cứu sâu hơn như sau: $(\boldsymbol{a})$ thực hiện nghiên cứu tại các đối tác khác nhau của chuỗi cung ứng điện tử để đưa ra được 
những hàm ý quản trị sâu hơn; $(\boldsymbol{b})$ mở rộng phạm vi nghiên cứu ở các lĩnh vực sản xuất kinh doanh khác nhau và so sánh sự khác biệt trong ảnh hưởng của các thành phần chia sẻ thông tin trong các chuỗi cung ứng thuộc các ngành sản xuất khác nhau; $(c)$ đánh giá chất lượng của chia sẻ thông tin trong việc sử dụng các thành phần chia sẻ thông tin trong chuỗi nhằm nâng cao hiệu quả quản lý chuỗi cung ứng, hay đánh giá tác động kiểm soát của chất lượng thông tin lên mối quan hệ của các thành phần chia sẻ thông tin và hiệu quả hoạt động chuỗi cung ứng...từ đó, đưa ra các kiến nghị cụ thể, bổ sung hoặc phản biện lại kết quả nghiên cứu này

\section{LÒ̀I CẢM ON}

Nghiên cứu này được tài trợ bởi Trường Đại học Bách Khoa- ĐHQG-HCM trong khuôn khổ đề tài mã số To-QLCN-2019-21, nhóm tác giả trân trọng cảm ơn Quý Trường. Bên cạnh đó, nhóm tác giả chân thành cảm ơn Quý công ty đã hỗ trợ nhóm tác giả thực hiện nghiên cứu, Quý Tạp chí và Quý phản biện đã có những ý kiến phản biện giúp nhóm tác giả hoàn thiện bài viết.

\section{Tài liệu tham khảo}

Akgün, A. E., Keskin, H., Byrne, J. C., \& Aren, S. (2007). Emotional and learning capability and their impact on product innovativeness and firm performance. Technovation, 27(9), 501-513.

Asamoah, D., Andoh-Baidoo, F. K., \& Agyei-Owusu, B. (2016). Examining the relationships between supply chain integration, information sharing, and supply chain performance: A replication study. Proceedings of the Twenty-second Americas Conference on Information Systems, San Diego, 4, 2749-2758.

Baihaqi, I., \& Sohal, A. S. (2013). The impact of information sharing in supply chains on organisational performance: An empirical study. Production Planning \& Control, 24(8/9), 743-758.

Barratt, M., \& Barratt, R. (2011). Exploring internal and external supply chain linkages. Evidence from the field. Journal of Operations Management, 29(5), 514-528.

Baxter, P., \& Jack, S. (2008). Qualitative case study methodology: Study design and implementation for novice researchers. The Qualitative Report, 13(4), 544-559.

Bontis, N., \& Serenko, A. (2009). A causal model of human capital antecedents and consequents in the financial services industry. Journal of Intellectual Capital, 10(1), 53-60.

Boon-itt, S., \& Wong, Y. C. (2011). The moderating effects of technological and demand uncertainties on the relationship between supply chain integration and customer delivery performance. International Journal of Physical Distribution \& Logistics Management, 41(3), 253-276.

Calantone, R. J., Cavusgil, S. T., \& Zhao, Y. (2002). Learning orientation, firm innovation capability, and firm performance. Industrial Marketing Management, 31(6), 515-524.

Chatzoudes, D., \& Chatzoglou, P. (2015). Supply Chain Integration (SCI) measured from an information sharing perspective: Examining its impact on business success. Proceeding of the 2015 IEEE 9th International Conference on Research Challenges in Information Science, Athens, 52-63.

Coombs, W. T., \& Holladay, S. J. (2011). Managing corporate social responsibility: A communication approach (1st ed.). West Sussex, UK: Wiley-Blackwell Publications. 
Creswell, J. W., \& Creswell, J. D. (2018). Research design: Qualitative, quantitative, and mixed methods approaches (5th ed.). Thousand Oaks, CA: Sage Publications.

Devaraj, S., Krajewski, L., \& Wei, J. C. (2007). Impact of eBusiness technologies on operational performance: The role of production information integration in the supply chain. Journal of Operations Management, 25(6), 1199-1216.

Eisenhardt, K. M., \& Graebner, M. E. (2007). Theory building from cases: Opportunities and challenges. Academy of Management Journal, 50(1), 25-32.

Eng, T. Y. (2006). An investigation into the mediating role of cross-functional coordination on the linkage between organizational norms and SCM performance. Industrial Marketing Management, 35(6), 762-773.

Flynn, B. B., Huo, B., \& Zhao, X. (2010). The impact of supply chain integration on performance: A contingency and configuration approach. Journal of Operations management, 28(1), 5871.

Huo, B., Zhao, X., \& Zhou, H. (2014). The effects of competitive environment on supply chain information sharing and performance: An empirical study in China. Production and Operations Management, 23(4), 552-569.

Kembro, J., \& Selviaridis, K. (2015). Exploring information sharing in the extended supply chain: An interdependence perspective. Supply Chain Management: An International Journal, 20(4), 455-470.

Klein, R., \& Rai, A. (2009). Interfirm strategic information flows in logistics supply chain relationships. MIS Quarterly, 33(4), 735-762.

Kocoglu, İ., İmamoğlu, S. Z., İnce, H., \& Keskin, H. (2011). The effect of supply chain integration on information sharing: Enhancing the supply chain performance. Procedia Social and Behavioral Sciences, 24, 1630-1649.

Le, T. A. L., \& Nguyen, H. B. (2009). Mạng sản xuất toàn cầu trong ngành điện tử [Global production network in the electronics industry]. Tạp chí khoa học Đại học quốc gia Hà Nội, Kinh tế và Kinh doanh, 25, 167-175.

Luck, L., Jackson, D., \& Usher, K. (2006). Case study a bridge across the paradigms. Nursing Inquiry, 13(2), 103-109.

Martin, J. H., \& Grbac, B. (2003). Using supply chain management to leverage a firm's market orientation. Industrial Marketing Management, 32(1), 25-38.

Nguyen, Q. M., \& Nguyen, T. Q. L. (2013). Xác định vị thế cạnh tranh của các phân ngành sản phẩm ngành điện tử - công nghệ thông tin Thành phố Hồ Chí Minh [Xác định vị thế cạnh tranh của các phân ngành sản phẩm ngành điện tử - công nghệ thông tin Thành phố Hồ Chí Minh]. Tạp chí phát triển Khoa học và Công nghệ, 16(1), 81-94.

Nguyen, T. D. (2013). Phương pháp nghiên cứu khoa học trong kinh doanh [Scientific research method in business] (2nd ed.). Ho Chi Minh, Vietnam: Nhà xuất bản Tài chính.

Nguyen, T. H. (2014). Nghiên cứu ảnh hưởng của niềm tin và trao đổi thông tin điện tử đến sự hợp tác và kết quả quản trị chuỗi cung ứng [Study the effects of trust and electronic communication on supply chain governance cooperation and outcomes]. Tạp chí Kinh tế và Phát triển, 205(2), 2-10. 
Nguyen, T. T. H., Tran, T. T., Ho, T. M. L., Le, H. Đ., Nguyen, T. Q., \& Truong, Q. H. (2015). Quản lý chất lượng chuỗi cung ứng: Một mô hình khái niệm [Supply chain quality management: a conceptual model]. Tạp chí phát triển Khoa học và Công nghệ, 18(4), 113-123.

Sezen, B. (2008). Relative effects of design, integration and information sharing on supply chain performance. Supply Chain Management: An International Journal, 13(3), 233-240.

Tổng cục thống kê. (2019). Niên giám thống kê 2018 [Statistical yearbook 2018]. Retrieved May 10, 2020, form https://www.gso.gov.vn/default.aspx?tabid=512\&idmid=5\&ItemID=19298

Tran, T. L., \& Huynh, T. N. (2016). Các yếu tố duy trì hoạt động đổi mới, cải tiến của doanh nghiệp công nghiệp điện tử Thành phố Hồ Chí Minh [Factors for maintaining innovation and innovation activities of electronics industry enterprises in Ho Chi Minh City]. Tap chí phát triển Khoa học và Công nghệ, 19(2), 67-76.

VEIA (Hiệp hội doanh nghiệp điên tử Việt Nam). (2017). Liên kết trong phát triển ngành công nghiệp điện tử ở Việt Nam là yếu tố thiết yếu [Integration in the development of the electronics industry in Vietnam is an essential factor]. Retrieved May 11, 2020, form http://www.veia.org.vn/default.asp?xt=xt1\&page=newsdetail\&newsid=9630

Wang, L., Pfohl, H.-C., Berbner, U., \& Keck, A. K. (2016). Supply chain collaboration or conflict? Information sharing and supply chain performance in the automotive industry. In U. Clausen, H. Friedrich, C. Thaller, \& C. Geiger (Eds.), Commercial transport: Proceedings of the 2nd interdiciplinary conference on production logistics and traffic 2015 (pp. 303318). Switzerland: Springer International Publishing.

Yin, R. K. (2015). Case study research: Design and methods (5th ed.). Thousand Oaks, CA: Sage Publications.

Zhou, H., \& Benton, J. W. C. (2007). Supply chain practice and information sharing. Journal of Operations Management, 25(6), 1348-1365. 